\title{
Assessing the Effectiveness of Distance Education within the Context of Traditional Classroom
}

\author{
Gabriel Kofi Boahen Nsiah', Mable Oti-Boadi ${ }^{2}$ \\ ${ }^{1}$ Department of Education, Faculty of Arts and Social Sciences, Valley View University, Accra, Ghana \\ ${ }^{2}$ Department of General Studies, Ghana Technology University College, Accra, Ghana \\ Email: gabrielnsiah@gmail.com, smallangel20022002@yahoo.com
}

Received 15 February 2015; accepted 15 May 2015; published 19 May 2015

Copyright @ 2015 by authors and Scientific Research Publishing Inc.

This work is licensed under the Creative Commons Attribution International License (CC BY). http://creativecommons.org/licenses/by/4.0/

c) (i) Open Access

\begin{abstract}
Distance education has become a platform for delivery of education around the globe. Nations are seizing the opportunities. This learning tool is offering and thereby providing anytime anywhere forms of education to bridge the educational gap in respective nations. In view of this expansion, assessing the effectiveness of distance education within the context of traditional classroom delivery of instruction is expedient. This will better inform educational institutions in planning a distance education program.
\end{abstract}

Keywords

Distance Education, Assessment, Effectiveness, Instructor, Technology

\section{Introduction}

Education plays a significant role in shaping a nation, and the proliferation of Internet-based educational opportunities has expanded distance learning modalities to all parts of the globe (Nsiah, 2011). This expansion has encouraged researchers to examine its effectiveness within the context of traditional classroom systems (Bernard, Abrami, Yiping, \& Borokhovski, 2004; Cavanaugh, Gillan, Kromrey, Hess \& Blomeyer, 2004; McIsaac \& Gunawardena, 1996). Assessment of student learning outcomes is the means by which educators determine how much students have learned in a course, and it measures the progress of students (Weller, 2003). In constructivist learning environments, assessment and learning are integrally related. In such environments, students are aware from the onset of what is expected of them. They are expected to demonstrate understanding of the subject matter and to apply their understanding in authentic situations (Comeaux, n.d.). According to Boud (1995), 
assessment methods and requirements probably have a greater influence on how and what students learn than any other individual factors.

\section{Assessment Methods}

Mateo and Sangra (2007) believed that quality of learning should not be measured only in terms of student learning achievement or success but should also be related to the effectiveness of the instruction that took place in the classroom. For this reason, Mateo and Sangra raised the development of a formative assessment system to a major feature necessary for distance education instruction. They therefore suggested that assessment must help to identify and apply improvements in the student learning process, through a permanent feedback (p. 9).

According to Comeaux (n.d.), instructors with a belief in and appreciation for constructivist learning, acknowledge the importance of using appropriate methods for evaluating students' performance in online courses. Comeaux commended the use of websites and electronic portfolios as excellent ways for students to demonstrate their competencies in a variety of areas. She is convinced that an electronic portfolio will provide students with a creative and efficient way of showcasing numerous authentic projects created by the students throughout their academic career.

Mateo and Sangra (2007) emphasized the fact that distance education experiences challenges to its competency in assessment and identification of the online student. In other words, it is sometimes unclear whether the course work is being done by the student him or herself or someone else, and authentic assessment is one way to provide greater assurance that the student on record is completing the work. This can be addressed through the integration of authentic assessments and project based activities that make cheating unlikely. Further, there are a number of programs that can now be integrated with testing software to provide additional test security. However, just as there is no way to fully guarantee test security in a traditional classroom, there are limitations and risks that must be acknowledged and addressed in the distance learning environment.

Despite the limitations associated with assessment and the many considerations that must be addressed when initiating a distance education program, there are substantial benefits to distance education. Most notably, distance education provides educational opportunities to many who would not otherwise have access to education, and this benefit makes addressing the critics and concerns worthwhile.

\subsection{Instructor's Effectiveness}

White and Weight (2000) asserted that effective distance education demands certain qualifications from the instructor that include both knowledge of the content area and the instructor's ability to communicate effectively within the distance education environment. Wolf (2006) posited that the complex nature of education at a distance requires participation in formal training and student evaluations that address instructor skills across the features of the medium that can be used to assess skills and improve instruction.

Carter (1995), like Wolf, acknowledged the importance of training. Carter posited that without well-planned and well-organized faculty training programs, the success of interactive distance education programs will be limited. And according to Cyrs (1997), institutions that fail to provide training for its distance education instructors run the risk of not attracting or retaining students.

Wolf (2006) found the following elements critical to success in teaching at a distance:

1) Minimum set of computer skills. Successful faculty should have a minimum set of computing skills such as experience using the computer, the Internet, and online applications before enrolling in training to teach online.

2) Ongoing faculty support. Effective distance education programs provide ongoing faculty support in the form of mentoring, shadowing, continuing education workshops, etc.

3) Motivation. Motivation is the most important element when choosing faculty to teach online. Successful distance education instructors are those willing to make the transition to the new environment with all the attendant risks and rewards.

4) Involvement in course design. There is need for faculty involvement in course design. If faculty are expected to design courses without the assistance of an instructional designer, instructional design theory should be included as part of the training to teach online.

5) Institutional support. Faculty success in distance education programs also depends on institutional support. Financial, human, and infrastructure resources are necessary in order to effectively design, maintain, and support the distance education training program (p. 60). 


\subsection{Academic Effectiveness}

In addition to the effectiveness of the instructor on a course-by-course basis, it is also important to consider and assess the educational value of distance education as a whole. Though it has substantial benefits, it has limitations and challenge that have to be considered and addressed. Cavanaugh et al. (2004) noted that in a distance environment students may feel isolated, parents may have concerns about children's social development, and students with language difficulties may experience a disadvantage in a text-heavy online environment. Curricular subjects requiring physical demonstrations of skill such as music, physical education, or foreign language may not be practical in a technology-mediated setting.

For example, Bond (2002) conducted a study involving the use of technology to deliver musical instruction to students isolated by distance. Bond found negative effects on performance quality, student engagement, and development and refinement of skills and knowledge. Despite using different approaches to engage the students, the barrier of distance was not adequately overcome in the study. This was attributed in part to the preparedness of the learners to make most effective use of the medium and also to limitations in the available knowledge regarding the best methods to effectively motivate and engage students in this form of learning.

In a meta-analysis relating to the effectiveness of distance education, Cavanaugh et al. (2004) compared results from 116 grades 3 - 12 web-based distance education programs with classroom-based teaching, including data for 7561 students from 1999 and 2004. The analysis showed that distance education did not outperform or underperform classroom instruction but was equal in effectiveness. This study showed that distance education can have the same effect on measures of student academic achievement when compared to traditional instruction. In an empirical investigation of student achievement and satisfaction in different learning environments involving online instruction, traditional face-to-face instruction, and a combination of online and traditional instruction, Lim et al. (2008) found that both distance education students and the combined learning groups had a significantly higher achievement than students in the traditional learning group. However, the results indicated students in the online learning and combined learning groups used the Internet more often and had better technological skills and experience prior to taking the course than students in the traditional learning group.

Chen and Jones (2007) conducted a survey of students in an accounting class to compare students' assessments of course effectiveness and overall satisfaction with the course. One group of students was enrolled in a traditional in-class section and another group in a blended learning section. The primary course delivery method was online instruction conducted by the same instructor. Overall perceptions of the course, instructor, and learning outcome were positive for both groups. The majority of students in the blended learning class indicated that they would take another accounting course using that approach if it were offered.

Despite the positive outcome, however, some interesting differences were noted. Specifically, students in the traditional setting were more satisfied with the clarity of instruction while students in the blended learning class felt more strongly that they gained an appreciation of the concepts in the field. The blended-learning group students also indicated more strongly that their analytical skills improved as a result of the course. The results suggested that the two delivery methods were similar in terms of final learning outcomes but that both may be improved (Chen \& Jones, 2007). By contrast, Rivera and Rice (2002) conducted research comparing student outcomes and satisfaction between traditional and web based course offerings and found that students were not completely satisfied with web based course offerings because of limited technological mastery and lower levels of motivation.

Wang (2004) examined the perceptions of Asian students while taking synchronous online courses in the United States. The research concluded that synchronous online courses are useful, but they cannot be substituted for face-to-face courses. The students complained of a lack of sense of learning community and informal interactions with classmates. The Asian students were nervous about speaking out in the synchronous online course because they were afraid of making grammatical mistakes. Language barriers were the biggest challenge for the Asian students in the synchronous online courses. The study identified several recommendations for improving the student experience when learning synchronously at a distance. These included suggestions to a) establish some regular face-to-face meetings for synchronous online courses; b) speak slowly in synchronous online courses (both the instructor and students); c) incorporate some asynchronous techniques to enhance learning in synchronous online courses; d) design some inter-group activities to encourage interactions in synchronous online courses; and e) summarize course discussions at the end of class. 


\section{Conclusion}

Effectively, distance education is seen as a solution for access to education. It caters to all types of people irrespective of background and nature of the situation. Students are satisfied with it in some situations and less or not satisfied in others. Like any instructional medium, distance education has its benefits and its deficits, and these must be considered within the totality of planning a distance education program.

\section{References}

Bernard, R. M., Abrami, P. C., Yiping, L., \& Borokhovski, E. (2004). A Methodological Morass? How We Can Improve Quantitative Research in Distance Education. Distance Education, 25, 175-198. http://dx.doi.org/10.1080/0158791042000262094

Bond, A. (2002). Learning Music Online: An Accessible Learning Program for Isolated Students. http://www.ncver.edu.au/research/proj/nr1013.pdf

Boud, D. (1995). Enhancing Learning Through Self Assessment. London: Kogan Page.

Carter, A. (1995). Developing Faculty Training for Interactive Distance Education. Innovations in Education and Training International, 32, 47-152. http://dx.doi.org/10.1080/1355800950320209

Cavanaugh, C. (2002). Distance Education Quality: Success Factors for Resources, Practices and Results. In R. Discenza, C. Howard, \& K. Schenk (Eds.), The Design and Management of Effective Distance Learning Programs (pp. 171-189). Hershey, PA: Idea Group.

Cavanaugh, C., Gillan, K. J., Kromrey, J., Hess, M., \& Blomeyer, R. (2004). Effects of Distance Education on K-12 Student Outcomes: A Meta-Analysis. Naperville, IL: Learning Point Associate.

Chen, C. C. \& Jones, K. T. (2007). Blended Learning vs. Traditional Classroom Settings: Assessing Effectiveness and Student Perceptions in an MBA Accounting Course. The Journal of Educators Online, 4, 1-15.

Comeaux, P. (n.d). Assessing Students’ Online Learning: Strategies and Resources. The Professional \& Organizational Development Network in Higher Education, 17(3), 2005-2006

Cyrs, T. E. (1997). Competence in Teaching at a Distance. In T. E. Cyrs (Ed.), Teaching and Learning at a Distance: What It Takes to Effectively Design, Deliver, and Evaluate Programs (pp. 15-18). San Francisco, CA: Jossey-Bass.

Lim, J., Kim, M., Chen, S. S., \& Ryder, C. E. (2008). An Empirical Investigation of Student Achievement and Satisfaction in Different Learning Environments. http://findarticles.com/p/articles/mi_m0FCG/is_2_35/ai_n27926193/?tag=content;col1

Mateo, J., \& Sangra, A. (2007). Designing Online Learning Assessment through Alternative Approaches: Facing the Concerns. http://www.eurodl.org/?keyword=online\%20learning\&article=294

McIsaac, M. S., \& Gunawardena, C. N. (1996). Handbook of Research for Educational Communications and Technology: A Project of the Association for Educational Communications and Technology. New York, NY: Simon \& Schuster Macmillan.

Nsiah, G. K. B. (2011). Case Studies in US Distance Education: Implications for Ghana’s Under-Served High Schools. Creative Education, 2, 346-353. http://dx.doi.org/10.4236/ce.2011.24049

Wang, C. M. (2004). Taking Online Courses in the United States: The Perspectives of Asian students from China, Korea, Singapore, and Taiwan. Proceedings of the E-Learn 2004 conference: World Conference on E-Learning in Corporate, Government, Healthcare, \& Higher Education (pp. 2466-2468). Norfolk, VA: Association for the Advancement of Computing in Education.

Weller, M. (2003). Deliveryiing Learning on the Net. Sterling, VA: Stylus.

White, K. W., \& Weight, B. H. (2000). The Online Teaching Guide. Boston: Allyn \& Bacon.

Wolf, P. D. (2006). Best Practices in the Training of Faculty to Teach Online. Journal of Computing in Higher Education, 17, 47-78. http://dx.doi.org/10.1007/BF03032698 